\title{
Phototoxic damage to cone photoreceptors can be independent of the visual pigment: the porphyrin hypothesis
}

\author{
Mélanie Marie ${ }^{1}$, Valérie Forster ${ }^{1}$, Stéphane Fouquet ${ }^{1}$, Pascal Berto ${ }^{1,2}$, Coralie Barrau ${ }^{3}$, Camille Ehrismann ${ }^{3}$, \\ José-Alain Sahel ${ }^{1,4,5}$, Gilles Tessier ${ }^{1}$ and Serge Picaud (10 ${ }^{1}$
}

\begin{abstract}
Lighting is rapidly changing with the introduction of light-emitting diodes (LEDs) in our homes, workplaces, and cities. This evolution of our optical landscape raises major concerns regarding phototoxicity to the retina since light exposure is an identified risk factor for the development of age-related macular degeneration (AMD). In this disease, cone photoreceptors degenerate while the retinal pigment epithelium (RPE) is accumulating lipofuscin containing phototoxic compounds such as A2E. Therefore, it remains unclear if the light-elicited degenerative process is initiated in cones or in the RPE. Using purified cone photoreceptors from pig retina, we here investigated the effect of light on cone survival from 390 to $510 \mathrm{~nm}$ in $10 \mathrm{~nm}$ steps, plus the $630 \mathrm{~nm}$ band. If at a given intensity $\left(0.2 \mathrm{~mW} / \mathrm{cm}^{2}\right)$, the most toxic wavelengths are comprised in the visible-to-near-UV range, they shift to blue-violet light $(425-445 \mathrm{~nm})$ when exposing cells to a solar source filtered by the eye optics. In contrast to previous rodent studies, this cone photoreceptor phototoxicity is not related to light absorption by the visual pigment. Despite bright flavin autofluorescence of cone inner segment, excitation-emission matrix of this inner segment suggested that cone phototoxicity was instead caused by porphyrin. Toxic light intensities were lower than those previously defined for A2E-loaded RPE cells indicating cones are the first cells at risk for a direct light insult. These results are essential to normative regulations of new lighting but also for the prevention of human retinal pathologies since toxic solar light intensities are encountered even at high latitudes.
\end{abstract}

\section{Introduction}

Lighting is rapidly changing with the introduction of light-emitting diodes (LEDs) in our homes, workplaces, and cities. These lighting modifications raise major concerns regarding phototoxicity to the retina and other ocular compartments ${ }^{1,2}$. In fact, all external tissues of the body including skin and ocular structures (conjunctiva, cornea, lens, and retina) are daily exposed to natural and

\footnotetext{
Correspondence: Serge Picaud (serge.picaud@inserm.fr)

'Sorbonne Université, INSERM, CNRS, Institut de la Vision, 17 rue Moreau, 75012 Paris, France

Université de Paris, Campus Saint Germain, 45 rue des Saints Pères, 75006 Paris, France

Full list of author information is available at the end of the article These authors contributed equally: Mélanie Marie, Valérie Forster Edited by N. Bazan
}

artificial lights. Light is a well-known environmental factor to cause diseases of the skin with associated ocular symptoms ${ }^{3}$. Epidemiological studies have also indicated that light, and more precisely blue light, is an identified risk factor for the development of age-related macular degeneration $(\mathrm{AMD})^{4}$. Blue light, whatever its origin (natural sunlight or artificial lightings), carries the highest energy in the visible range and can thus be very deleterious to cells. In addition, many natural molecules like the visual pigment derivative $\mathrm{A} 2 \mathrm{E}$ are present in retinal cells and absorb light in the blue range rendering cells highly photosensitive to blue light ${ }^{5,6}$.

To further understand the etiology of AMD, different animal and cell models were used to uncover the mechanisms underlying blue light toxicity. In rodents,

\section{(c) The Author(s) 2020}

(c) (i) Open Access This article is licensed under a Creative Commons Attribution 4.0 International License, which permits use, sharing, adaptation, distribution and reproduction cc) in any medium or format, as long as you give appropriate credit to the original author(s) and the source, provide a link to the Creative Commons license, and indicate if changes were made. The images or other third party material in this article are included in the article's Creative Commons license, unless indicated otherwise in a credit line to the material. If material is not included in the article's Creative Commons license and your intended use is not permitted by statutory regulation or exceeds the permitted use, you will need to obtain permission directly from the copyright holder. To view a copy of this license, visit http://creativecommons.org/licenses/by/4.0/. 
rhodopsin and cone pigments have been suggested as the death-mediating chromophores to photoreceptors ${ }^{7}$. More precisely, photoreceptor degeneration was shown to be caused by prolonged or constitutive opsin activation by light $^{8,9}$. Opsin regeneration is required without the need for complete phototransduction cascade ${ }^{8,10,11}$. Consistent with this hypothesis, intermittent blue light exposure induced the death of short wavelength sensitive cones in nonhuman primates whereas green light induced a transient loss of green light sensitive cones ${ }^{12}$. In vitro light damage to cones was only examined using the $661 \mathrm{~W}$ cell line, which has lost its typical morphology of photoreceptors $^{13-15}$. With these cells, light was found to be more toxic in the presence of all-trans retinal, which is obtained by light conversion of the natural opsin chromophore, the 11-cis retinal ${ }^{13}$.

Because artificial and natural light toxicities were never examined on primary isolated cone photoreceptors, we here investigated the effect of $10 \mathrm{~nm}$ wavelength bands onto freshly purified porcine cone photoreceptors ${ }^{16}$. We applied either the same light intensity at all wavelengths to define the most toxic or at intensities of a solar source filtered by the eye optics. Results were interpreted based on autofluorescence examinations of cones and of cone inner segment emission-excitation matrix. Finally, we measured sun light intensities in Paris to compare them with those used in this study.

\section{Results}

\section{Phototoxicity to isolated cone photoreceptors}

To investigate if phototoxicity onto cone photoreceptors could be an early event in ocular diseases and acute light burns, we measured light toxicity on primary isolated cone photoreceptors from pig retinas (Fig. 1a, b) using our dedicated light-emitting device delivering $10 \mathrm{~nm}$-wide bands of light $\mathrm{t}^{5}$. We first characterized the cell preparation regarding the cell morphology, viability and purity with cone specific markers such as cone arrestin and opsins. Cells exhibited a typical cone photoreceptor morphology with inner and outer segment, cell body and synaptic ending (Fig. 1a, b). The cell preparation was highly enriched with cone photoreceptors since $93 \%$ of cells with a DAPI-stained nucleus were immunopositive with a cone arrestin antibody (Figs. 1c, 2a-f). Furthermore, when assessing the cell viability of our preparation with calcein green, we counted that $98 \%$ of viable cells were cone-arrestin immunopositive (Figs. 1c, 2a-f). To further characterize the isolated cone photoreceptors, we used cone opsin antibodies against either the blue S-opsin or the green M-opsin. Among isolated cells with a DAPI stained nucleus, $35 \%$ of them exhibited an outer segment immunopositive for $\mathrm{M}$-opsin (green cones), only $1.3 \%$ of cells exhibited S-opsin immunopositive outer segment (blue cones) (Figs. 1d, 3i-p). Because 98\% of purified cells were cone photoreceptors as indicated by their immunolabelling for the cone arrestin protein, the opsinnegative cells, $63 \%$ of purified cells, were most likely cone photoreceptors that had lost their outer segment during the dissociation procedure without losing their viability.

We first exposed these purified cones to light at a given irradiance $\left(0.2 \mathrm{~mW} / \mathrm{cm}^{2}\right)$ for $15 \mathrm{~h}$ for each tested wavelength band (390-510 in $10 \mathrm{~nm}$ steps, plus the $630 \mathrm{~nm}$ band) to characterize their photosensibility to artificial light (Fig. 1e, f). Blue-violet light (390-450 nm) emerges as highly toxic, with a maximum toxicity between 390 and $410 \mathrm{~nm}$ and a toxicity decreasing with increasing radiation wavelength up to $450 \mathrm{~nm}$ (Fig. 1f). These data demonstrate the potential toxicity of monochromatic LED light within the near-UV and blue-violet range.

In a second step, we normalized light irradiances to account for eye optic absorption and to evaluate effect of sunlight levels reaching the retina, as previously described $^{5}$. Under these conditions, the most toxic bands were shifted to the $410-460 \mathrm{~nm}$ range with a peak of toxicity at 430 and $440 \mathrm{~nm}$ (Fig. 1e, g). Indeed, at $430 \mathrm{~nm}$, the survival rate decreased to $6 \%$ of the number of cone photoreceptor surviving in darkness. No significant toxicity was observed with green light (Fig. 1g) although the preparation contained 35\% M-opsin-positive (green) cones (Fig. 1d). To investigate if the cell toxicity was related to opsin absorption, we quantified the number of surviving cells which were immunopositive for the M-opsin. Surprisingly, the ratio of $\mathrm{M}$-opsin positive cells in surviving cones was decreased with a statistical significance under blue light (430 and $440 \mathrm{~nm}, \mathrm{Fig}$. 1h), indicating that the relative loss of these green cones was not correlated to the amplitude of the M-opsin absorption spectrum; the toxicity was greater at $430-440 \mathrm{~nm}$ than at $480 \mathrm{~nm}$ (Fig. $1 \mathrm{~h})$. We attributed this greater blue toxicity onto greensensitive cones to their cell morphological integrity and the likely light sensitivity of the inner segment (see below). Indeed, the green $\mathrm{M}$-opsin immunolabelling is restricted to the outer segment, therefore it can only be seen in cone photoreceptors with intact outer/inner segments. The absence of greater green light toxicity onto green cones suggests that, in our experimental conditions, light toxicity was independent of the visual pigment.

\section{Nonvisual pigments and autofluorescence in cone photoreceptors}

To further understand the origin of this phototoxicity, we investigated the presence of other photosensitive pigments in cone photoreceptors. On ex vivo alive retinas, we localized a bright autofluorescence in cone inner segments across species from pigs to nonhuman primates and even humans (Fig. 4a). This bright fluorescence remained on vertical sections that were prepared by vibratome sectioning from the fresh tissue (Fig. 4b, d). 

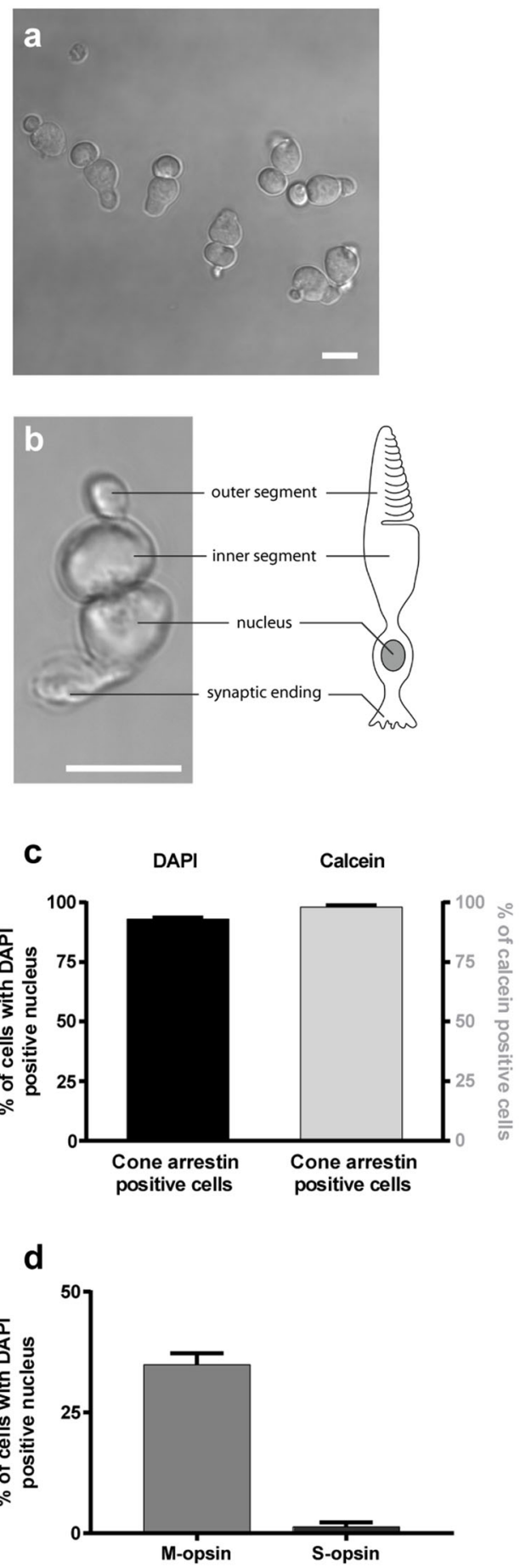
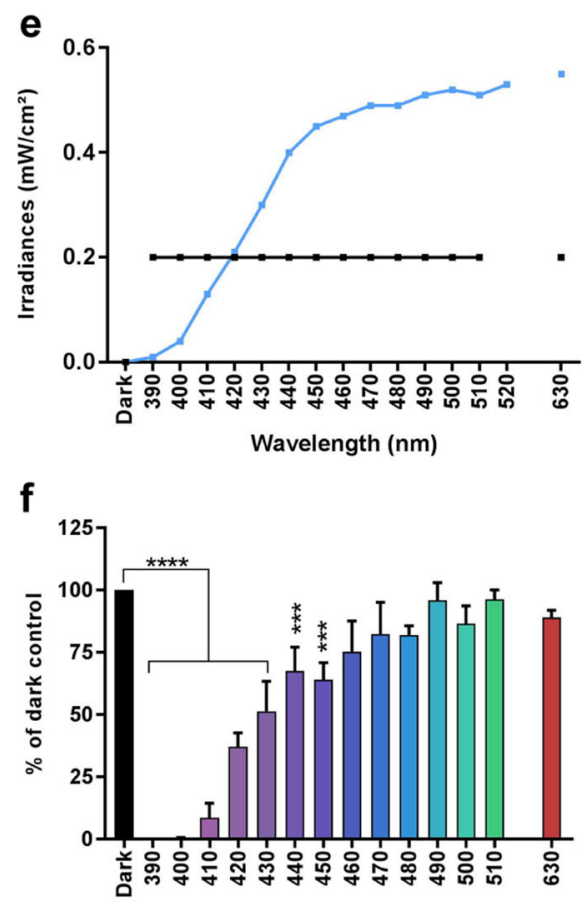

Wavelength $(\mathrm{nm})$

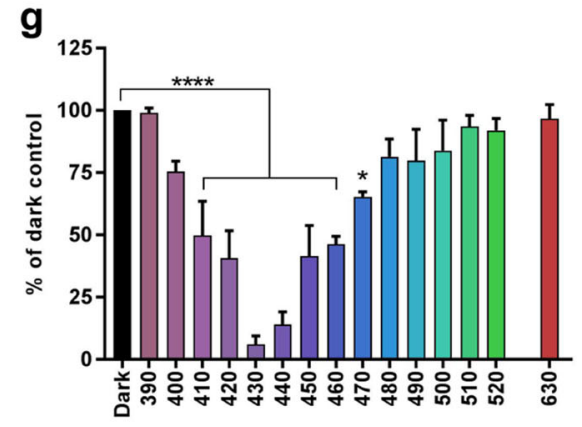

h

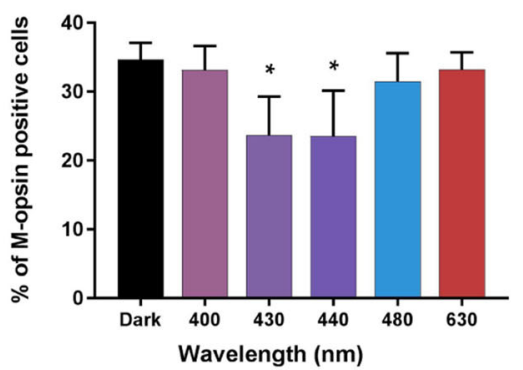

Fig. 1 (See legend on next page.)

Finally, in purified primary cone photoreceptors, the bright fluorescence of their inner segments confirmed the high purity of our preparations from pig, nonhuman primate and even from postmortem human tissue (Fig. 4e, $\mathrm{g}, \mathrm{h}, \mathrm{j})$. By contrast, rod inner segments generate a weaker autofluorescence, slightly visible on the peripheral 
(see figure on previous page)

Fig. 1 Phototoxicity to isolated primary cone photoreceptors. a, b Morphology of isolated porcine cone photoreceptors showing outer segment, inner segment, cell body and axon terminal. c Characterization of the cell preparation showing that cone arrestin immunopositive photoreceptors represented $93 \%$ of purified cells with DAPI-stained nucleus and $98 \%$ of the calcein-stained viable cells, $n=3$. d Quantification of green M-opsin and blue S-opsin immune-positive cone photoreceptors in the population among isolated cells, $n=3$. e Irradiance levels in the two sets of experiments, either at identical irradiance $(\mathbf{f})$ or normalized to the solar light spectrum reaching the retina $(\mathbf{g})$. Spectra of cell viability under the same light irradiance level for all tested $10 \mathrm{~nm}$ wavelength bands $(\mathbf{f})$ or after normalizing the irradiance levels to the solar spectrum reaching the retina $(\mathbf{g})$. Viability was assessed by calcein staining after a $15 \mathrm{~h}$-light exposure to $10 \mathrm{~nm}$-wide bands of light and expressed as percentage of dark control condition. $\mathbf{f} n=3$ for 390, 460, 470, $510 \mathrm{~nm}, n=4$ for $410,420,450,490,500 \mathrm{~nm}, n=5$ for 400, 430, 440, 480, 630. g $n=5$ for 390, 460, 470, $510,520 \mathrm{~nm}, n=7$ for all other wavelengths. $\mathbf{h}$ Relative ratio of green M-opsin positive cone photoreceptors in darkness, or after exposure to different wavelengths with irradiance levels normalized to the solar spectrum reaching the retina as in $\mathbf{g}, n=3$. Data are expressed as mean \pm SEM. Each $10 \mathrm{~nm}$ spectral band is designated by its central wavelength. Experiments were performed at least in three independent primary cone photoreceptors preparations. ANOVA followed by Dunnett's post hoc tests were used to compare variances of all groups. Differences between samples and dark control were considered to be significant when $p<0.05\left({ }^{*}\right), p<0.01\left({ }^{* *}\right), p<0.001\left({ }^{* * *}\right)$ or $p<0.0001\left(^{* * *}\right)$. Scale bars represent $10 \mu \mathrm{m}$.
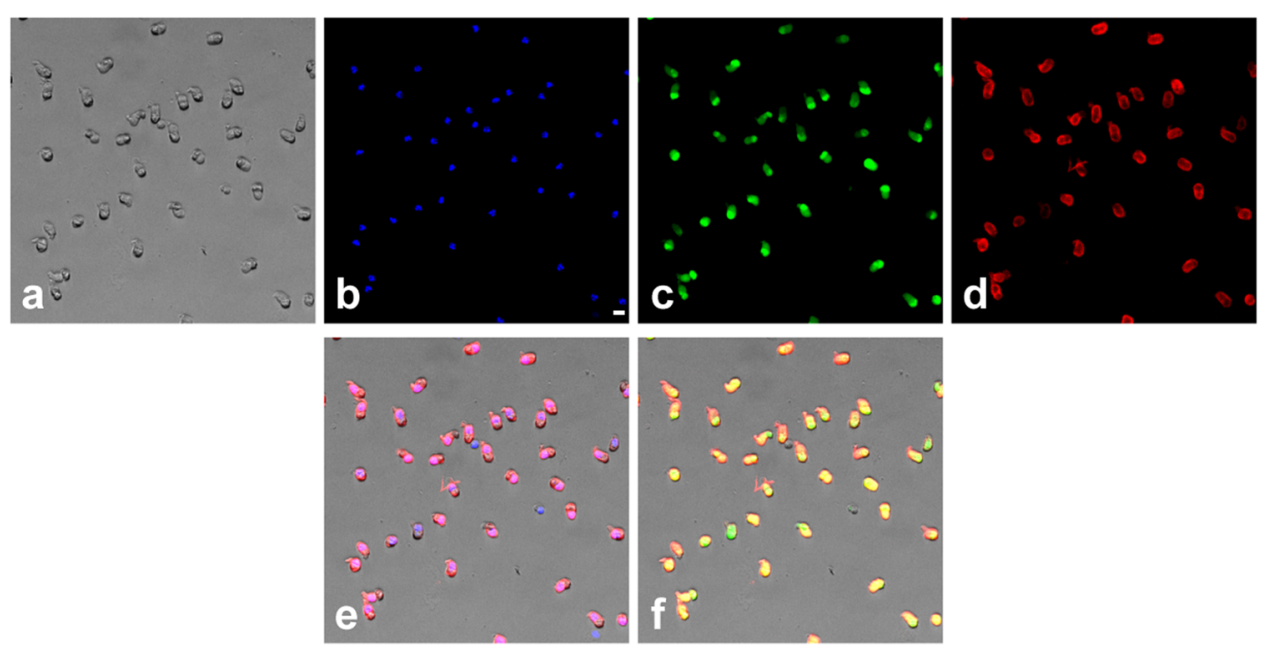

Fig. 2 Assessment of cone purity. Cell preparation showing the light transmitted image (a), the DAPI nuclear staining (b), calcein green staining for viable cells (c) and the immunoreactive cone arrestin staining (d). The merged images DAPI/cone arrestin (e) and calcein/cone arrestin (f) indicate that most isolated viable cells are cone photoreceptors as quantified in Fig. 1d. The scale bar represents $10 \mu \mathrm{m}$.

flat-mounted retina of the nonhuman primate (Fig. 4b, d). An intense autofluorescence was also localized in cell bodies of retinal ganglion cells (Fig. 5a) and in their axon bundles (Fig. 5b). This autofluorescence in all these structures was attributed to mitochondria because it colocalized to the mitochondrial ATP synthase immunolabelling (Figs. 6, 7).

\section{Excitation/emission spectra of cone autofluorescence}

The autofluorescence in cone photoreceptor inner segment was bright $\left(\mathrm{I}_{488}\right)$ upon $488 \mathrm{~nm}$ excitation, weak upon blue excitation at $405 \mathrm{~nm}\left(\approx 33 \%\right.$ of $\left.\mathrm{I}_{488}\right)$, and below detection thresholds $\left(<1 \%\right.$ of $\left.\mathrm{I}_{488}\right)$ upon red $(594 \mathrm{~nm})$ and far red $(644 \mathrm{~nm})$ excitation wavelengths. To investigate the nature of this autofluorescent chromophore, we measured its fluorescence emission spectrum on freshly isolated pig retinas excited by a $475 \mathrm{~nm}$ laser source (Fig. $8 \mathrm{a}, \mathrm{b})$. Data showed a high fluorescence emission peak centered at $550 \mathrm{~nm}$ in the cone inner segment (Fig. 8a, b). This chromophore is unlikely to provoke the light toxicity on cone photoreceptors, as one would have expected to see a peak of toxicity at the absorption peak $(488 \mathrm{~nm})$ under the equal illumination irradiances (Fig. 1f). To further define the spectral signatures of chromophores in cones, an excitation-emission matrix was measured in their inner segments (Fig. 8c). Cone inner segments were exposed to wavelengths ranging from 300 to $490 \mathrm{~nm}$ in $15 \mathrm{~nm}$ increments, and the corresponding emission spectra were recorded. The resulting excitation-emission matrix was normalized to compensate for variations in the intensity of the excitation source (Fig. 8c). Despite a measurement uncertainty below $400 \mathrm{~nm}$ due to the lower power of our excitation source, this analysis indicated that the green autofluorescence $(540 \mathrm{~nm})$ had two excitation peaks at 350 and $470 \mathrm{~nm}$, which are highly reminiscent of the flavin spectral properties, supporting further a 

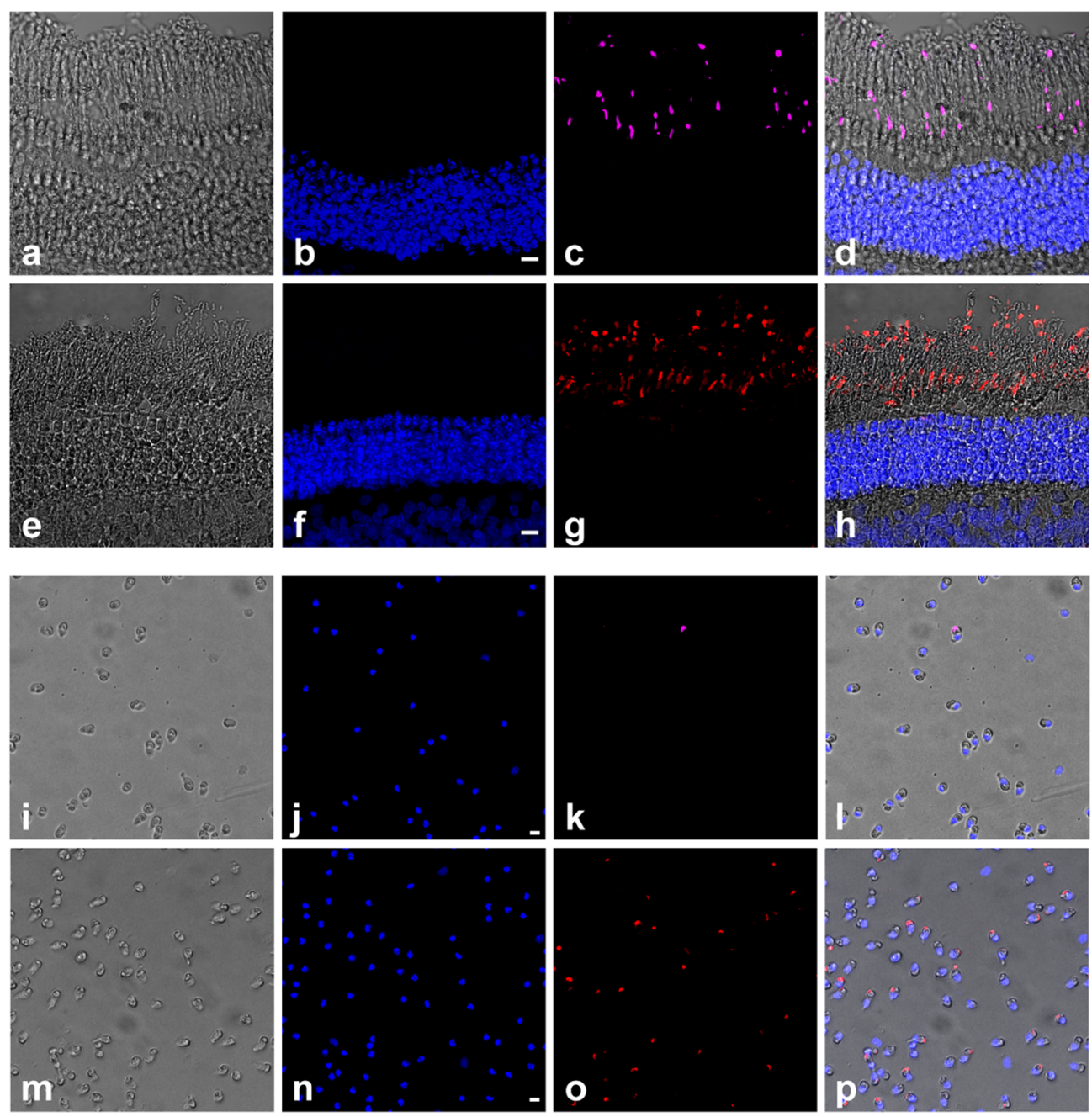

Fig. 3 Identification of cone photoreceptors types by immunoreactive opsin staining. Vertical sections $(\mathbf{a}-\mathbf{h})$ and isolated porcine cones (i-p) showing the blue S-opsin $(\mathbf{c}, \mathbf{k})$ and green M-opsin $(\mathbf{g}, \mathbf{o})$, the DAPI nuclear staining $(\mathbf{b}, \mathbf{f}, \mathbf{j}, \mathbf{n})$ the light transmitted images $(\mathbf{a}, \mathbf{e}, \mathbf{i}, \mathbf{m})$ and the merged images $(\mathbf{d}, \mathbf{h}, \mathbf{l}, \mathbf{p})$. Scale bars represent $10 \mu \mathrm{m}$.

previous proposition for cone in vivo autofluorescence rather than other proposed alternatives ${ }^{17}$. In this analysis, we observed an additional red autofluorescence $(610 \mathrm{~nm})$ with an excitation peak at $350 \mathrm{~nm}$ (Fig. 8c), which could be attributed to porphyrins ${ }^{18-20}$. This absorption by porphyrins extending in the blue range is consistent with the observed spectrum of phototoxicity on cone photoreceptors (Supplementary information 2). The potential implication of porphyrins in cone phototoxicity is further supported by their known photosensitization ${ }^{18}$.

\section{Discussion}

Phototoxicity of mouse rod photoreceptors was previously attributed to light absorption by rhodopsin ${ }^{10,11}$. We here observed a high toxicity of visible-to-near-UV light to all cone photoreceptors independently of their spectral sensitivity. Blue light was also shown to produce irreversible damage exclusively to short-wavelength sensitive cones in nonhuman primates but green light did not irreversibly damage middle-wavelength cones $^{12}$. This specific blue light damage of short-wavelength cones could be related to their greater vulnerability compared to other cones ${ }^{21}$. The spectrum of cone damage is consistent with the presence of a photosensitive chromophore with a spectral sensitivity in the visible-near-UV range. As cone cell damage was also observed in cones having lost their outer segment, this photosensitive chromophore is likely located outside this specific cell compartment. The measured cone excitation-emission matrix is consistent with high levels of both flavins and porphyrins in cone photoreceptor inner segment. Their location in cone inner segment is in agreement with their high concentrations in mitochondria ${ }^{22,23}$ and with the greater density of these organelles in the cone inner segment ${ }^{24}$. The absence of 


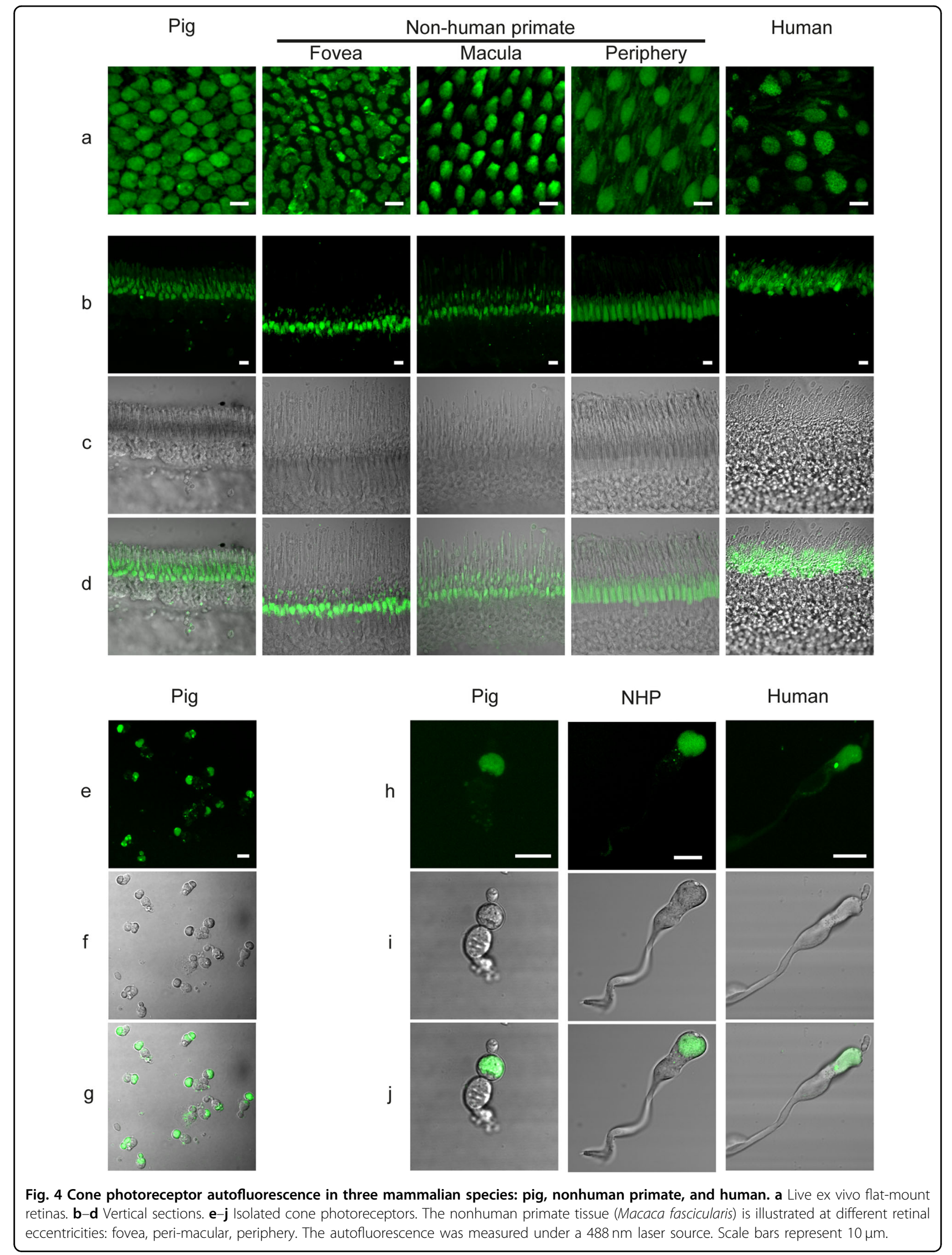


increased phototoxicity at the blue peak of flavin absorption indicates that the phototoxicity is more likely induced by porphyrins. By contrast, the overlap between published absorption spectra of porphyrins and the light toxicity on cone photoreceptors which we measured at

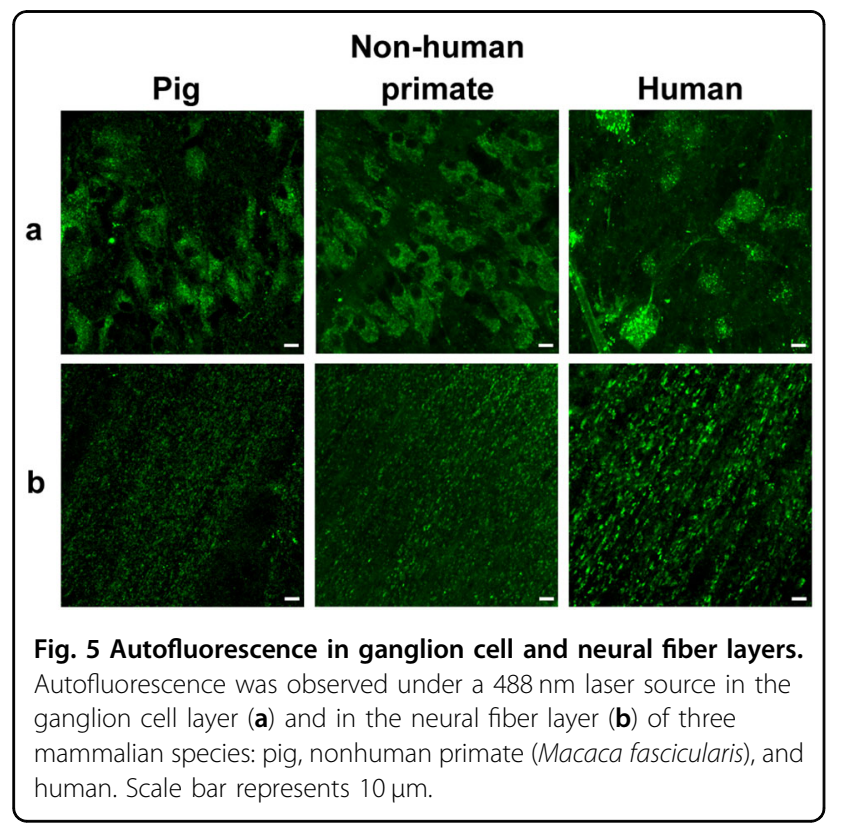

equal irradiance (Supplementary information 2) supports the porphyrin implication. In addition, the phototoxicity of porphyrin derivatives is widely known and taken to advantage in photodynamic therapy to erase cancer cells by light ${ }^{25-27}$.

Blue light has been defined as a risk factor in AMD, which is characterized by the macular loss of cone photoreceptors ${ }^{4}$. Here, normalizing the light irradiance to the solar spectrum reaching the retina, we found out that the most toxic range is located within blue light at $425-445 \mathrm{~nm}$ because most of the near-UV light is filtered by the anterior segment of the eye. This toxicity range was evaluated using moderate irradiances $\left(0.39 \mathrm{~mW} / \mathrm{cm}^{2}\right.$ at $440 \mathrm{~nm}$ ) and overlaps the toxic light range previously determined on RPE aging models using higher irradiances $^{5}\left(1.09 \mathrm{~mW} / \mathrm{cm}^{2}\right.$ at $\left.440 \mathrm{~nm}\right)$. A direct cone insult may therefore prevail over the RPE cell damage in the early phases of AMD. Filtering out these blue wavelengths selectively may efficiently protect from AMD development while barely affecting color vision and circadian rhythms.

These findings could be extended to other tissues daily exposed to blue-violet light such as the skin and ocular surface and may explain symptoms in several diseases with an increased sensitivity to photo-oxidative stress ${ }^{3}$. Even if most of the injury is induced by UV-light, our

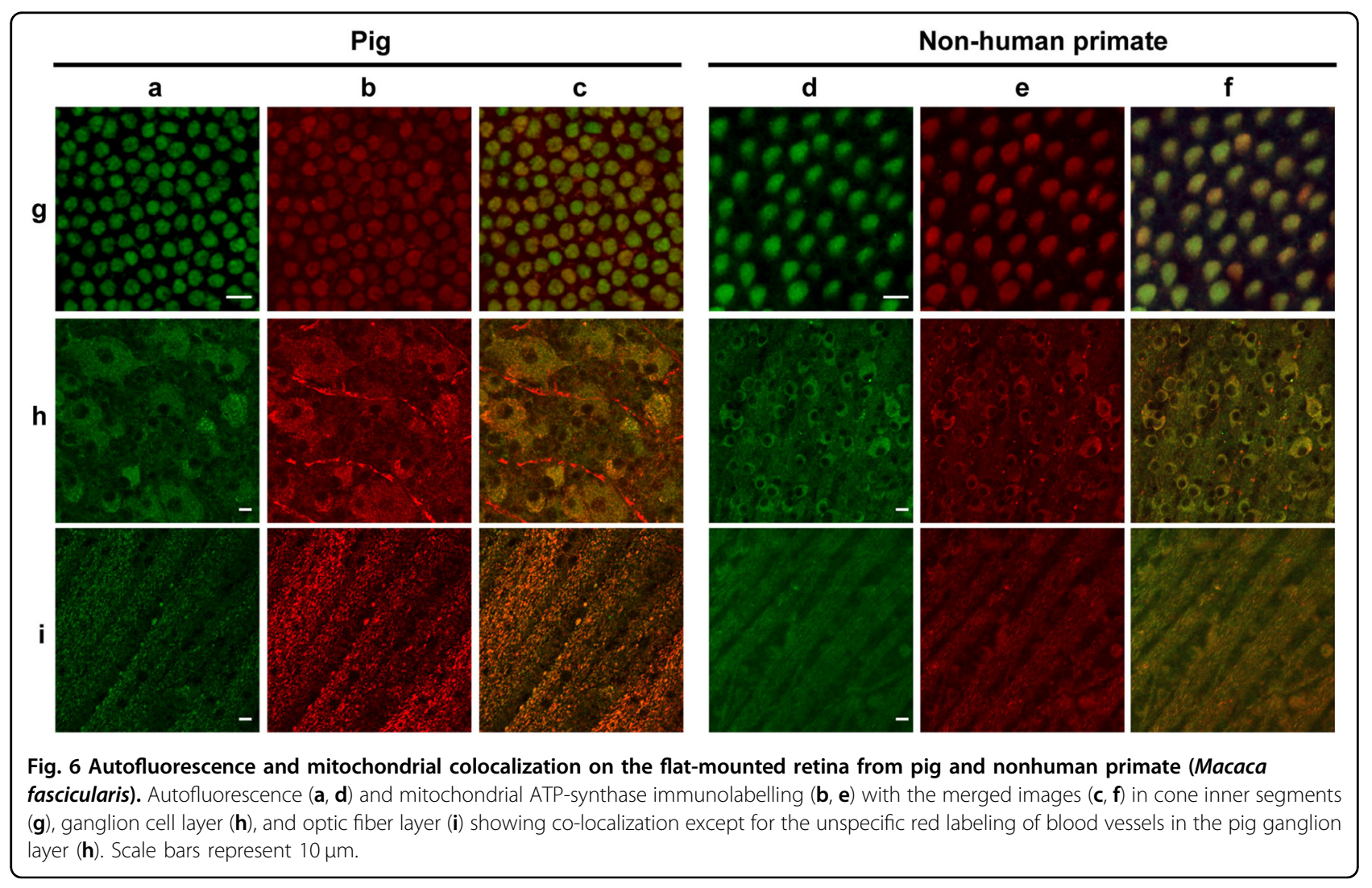




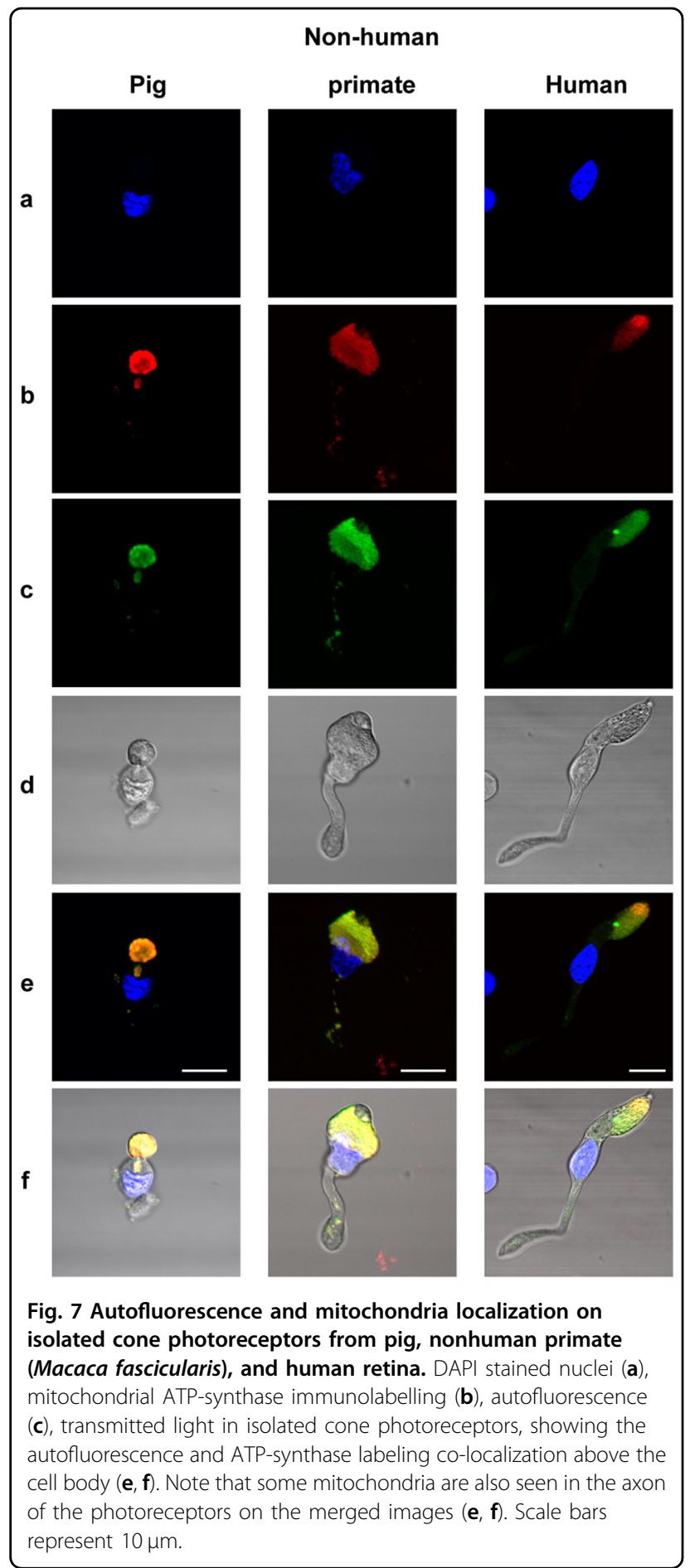

study with a constant spectral irradiance (Fig. 1f) indicates that blue-violet light and thus LED light exposure can contribute to cell damages as reported previously on skin cells $^{28}$. Indeed, visible light penetrates deeper than UV light, and blue-violet light can strongly contribute to oxidative stress in skin cells ${ }^{28}$. In corneal cells at the eye surface, both UV and blue-violet light exposures can contribute to the development of pathologies like the dryeye syndrome $\mathrm{e}^{29,30}$.

To investigate the relevance of these results to human pathologies, we compared our toxic light irradiances to daily light levels. The irradiance of $0.39 \mathrm{~mW} / \mathrm{cm}^{2}$ over a $10 \mathrm{~nm}$ light band centered at $440 \mathrm{~nm}$ used in vitro corresponds approximately to $0.93 \mathrm{~mW} / \mathrm{cm}^{2}$ in the same spectral band at the corneal level for a 40-year-old person. Comparatively, on a sunny morning (11:00 a.m.) in Paris during summer (August 29th, 2017), the irradiance level reached $0.46 \mathrm{~mW} / \mathrm{cm}^{2}$ (Table 1 ) over the $10 \mathrm{~nm}$-wide band centered at $440 \mathrm{~nm}$ when pointing $15^{\circ}$ downward a calibrated spectroradiometer, towards low-reflecting surfaces on the fifth floor of a building with an almost clear view, East orientation (Supplementary information 1). Over this very narrow band $(440 \pm 5 \mathrm{~nm})$, the irradiance measured on a bright morning at the relatively high latitude of Paris (Table 1) is only half the irradiance causing in vitro toxicity in our experiments. Taking into account the effect of other toxic wavelength bands $(410-460 \mathrm{~nm})$, lower latitudes, or higher albedos, a pedestrian can encounter toxic blue light levels on a sunny summer day. Fortunately, the 15-h exposition inflicted on isolated cone photoreceptors is unlikely, but cumulative effects over a week could become toxic since mitochondrial renewal is not finalized in a day: complete mitochondrial fusion-fission cycles were reported to take 16 days in the adult mouse ${ }^{31}$. These data strongly indicate that cone phototoxicity can occur even at moderate latitudes, or under artificial lighting.

This cell toxicity mechanism can easily explain retinal damage observed when staring at the sun during solar eclipses $^{32}$ or following indirect ground reflection in more exposed countries ${ }^{33,34}$. This photosensitization could also accelerate the degenerative process in the context of retinal diseases like retinitis pigmentosa showing greater sensitivity of cones to oxidative stress ${ }^{24}$. Because the described phototoxicity of cone photoreceptors can affect all the population including children, it is further reinforcing the concerns raised by the use of high-intensity LEDs with high blue contents ${ }^{1,2}$.

\section{Materials and methods \\ Mammalian retinas}

Porcine eyes were bought at a local slaughterhouse in agreement with the local regulatory department and the slaughterhouse veterinarians (agreement FR75105131). This procedure adheres to the European initiative for restricting animal experimentation because not a single animal was euthanized for our experimentation. Eyes 


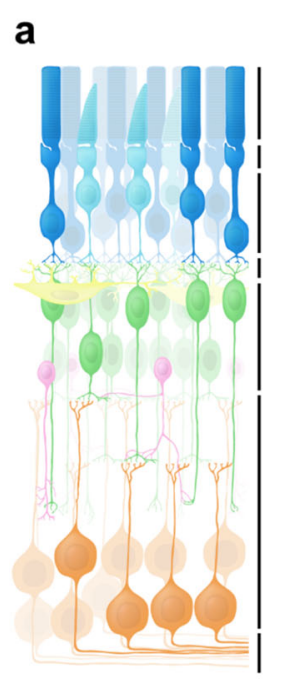

POS

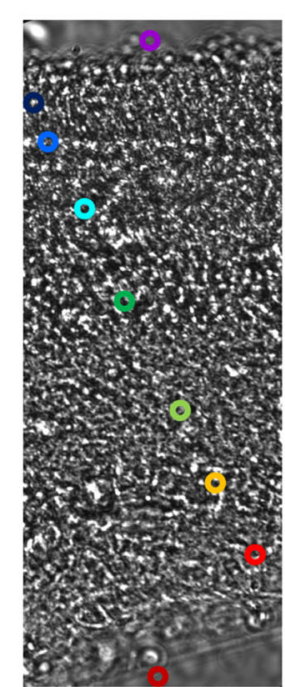

b

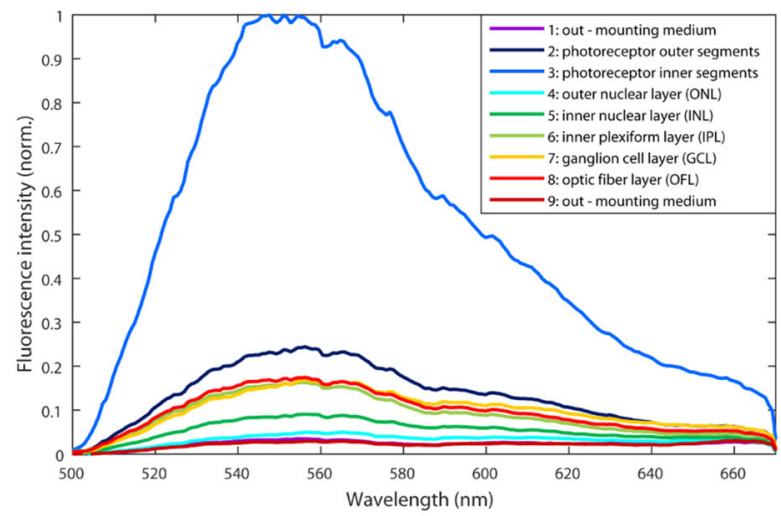

C

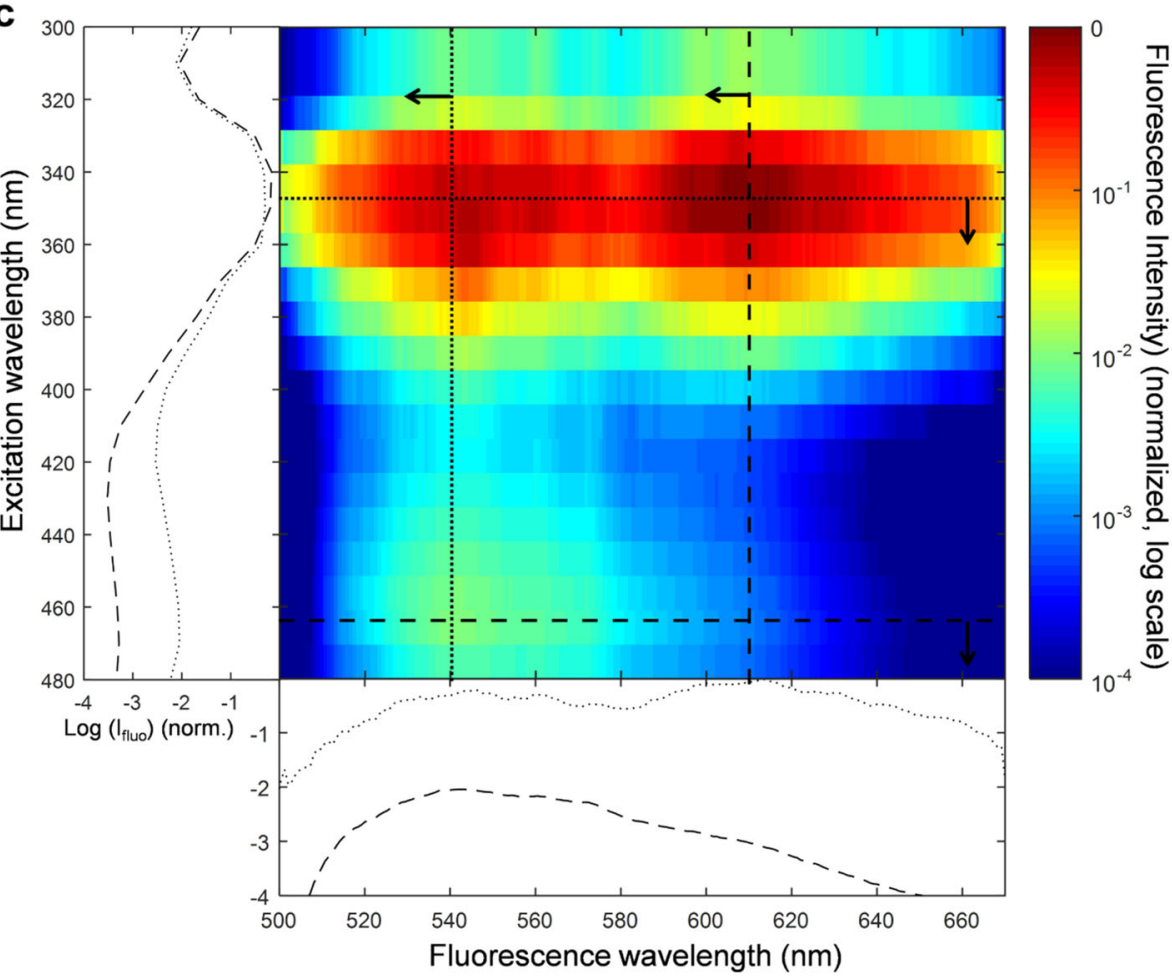

Fig. 8 Excitation and emission spectra in the porcine retina. a Freshly prepared vertical section of a live pig retina showing the locations used to measure emission spectra presented in $\mathbf{b}$. $\mathbf{b}$ Emission spectra in the different retinal layers showing a peak at $550 \mathrm{~nm}$ under a $475 \mathrm{~nm}$ laser excitation source. c excitation-emission matrix on a cone inner segment exposed to wavelengths ranging from 300 to $490 \mathrm{~nm}$ in $15 \mathrm{~nm}$ increments. POS: photoreceptors outer segments, PIS: photoreceptor inner segments, ONL: outer nuclear layer, OPL: outer plexiform layer, INL: inner nuclear layer, IPL: inner plexiform layer, GCL: ganglion cell layer, OFL: optic fiber layer.

were taken from animals daily sacrificed for food production.

Nonhuman primate retinas were prepared using eyes received from adult macaques (Macaca fascicularis) that were terminally anesthetized for unrelated studies. All animal experiments and procedures were ethically approved by the French "Ministère de l'Education, de l'Enseignement Supérieur et de la Recherche" and were carried out according to institutional guidelines in adherence with the National Institutes of Health guide for the care and use of laboratory animals as well as the Directive 2010/63/EU of the European Parliament. 
Table 1 Comparison of light irradiances used for in vitro experiments and measured outdoor in Paris.

\begin{tabular}{|c|c|c|c|}
\hline Wavelength (nm) & $\begin{array}{l}\text { Cone irradiances } \\
\text { in vitro }\left(\mathrm{mW} / \mathrm{cm}^{2}\right)\end{array}$ & $\begin{array}{l}\text { Corresponding cone irradiances at the } \\
\text { corneal level in a } 40 \text { year-old eye } \\
\left(\mathrm{mW} / \mathrm{cm}^{2}\right)\end{array}$ & $\begin{array}{l}\text { Irradiances at the corneal level measured in Paris } \\
\text { August } 29 \text { th, } 2017,11: 00 \text { am, East orientation, 5th } \\
\text { floor of a building with an almost-clear view, sensor } \\
\text { downard }-15^{\circ} \text { towards a low reflecting ground } \\
\left(\mathrm{mW} / \mathrm{cm}^{2}\right)\end{array}$ \\
\hline 400 & 0.04 & 2.00 & 0.31 \\
\hline 410 & 0.13 & 1.86 & 0.38 \\
\hline 420 & 0.22 & 1.22 & 0.39 \\
\hline 430 & 0.31 & 0.97 & 0.39 \\
\hline 440 & 0.39 & 0.93 & 0.46 \\
\hline 450 & 0.48 & 1,00 & 0.53 \\
\hline 460 & 0.44 & 0.83 & 0.56 \\
\hline 470 & 0.45 & 0.80 & 0.58 \\
\hline 480 & 0.56 & 0.95 & 0.59 \\
\hline 490 & 0.54 & 0.87 & 0.57 \\
\hline 500 & 0.51 & 0.78 & 0.61 \\
\hline 510 & 0.50 & 0.75 & 0.59 \\
\hline 520 & 0.69 & 1.00 & 0.60 \\
\hline 630 & 0.56 & 0.69 & 0.60 \\
\hline
\end{tabular}

Comparison between irradiance levels integrated over $10 \mathrm{~nm}$-wide light bands (designated by their central wavelengths) on isolated cones, their correspondence at the corneal level for the different wavelengths and measured outdoor irradiances in Paris on a sunny morning (11:00 am) on August 29th, 2017, East orientation, 5th floor of a building, light sensor oriented at $-15^{\circ}$ downward.

Postmortem human ocular globes from donors were acquired from the School of Surgery (Ecole de Chirurgie, Assistance Publique Hôpitaux de Paris, Paris, France, CODECOH DC-2015-2400). The protocol was approved by the IRBs of the School of Surgery and the QuinzeVingts National Ophtalmology Hospital (Paris, France). All experiments on postmortem human retinal explants were performed according to the local regulations, as well as the guidelines of the Declaration of Helsinki.

\section{Tissue preparation}

Eyes were cleaned up from muscles and incubated during 2 min in Pursept-AXpress (Thermo Fisher Scientific, Waltham, MA, USA) for disinfection. The anterior segment was cut along the limbus to remove the cornea, lens and vitreous. The retina was carefully removed from the eyecup and placed into $\mathrm{CO}_{2}$ independent medium (Life Technologies, Carlsbad, CA, USA). A $1 \mathrm{~cm}^{2}$ piece was cut and either immediately flat-mounted in Permafluor medium (Thermo Fisher Scientific) or included in $2-4 \%$ low melting agarose dissolved in a pre-warmed $\left(+37^{\circ} \mathrm{C}\right)$ custom modified Neurobasal A medium without any photosensitizer such as phenol red, riboflavin, folic acid and aromatic amino acids (modified NBA, Life Technologies) for retinal sectioning. Transversal slices of
$100 \mu \mathrm{m}$ thickness were cut using a vibrating microtome (Leica, Wetzlar, Germany) in modified NBA medium and then mounted in Permafluor medium (Thermo Fisher Scientific). Images were acquired without further delays.

\section{Cell isolation}

Cone photoreceptors were purified by lectin-panning selection as previously described ${ }^{16}$ and seeded in black clear bottom 96-well plates in a custom modified Neurobasal A medium without any photosensitizer such as phenol red, riboflavin, folic acid and aromatic amino acids (modified NBA, Life Technologies) for light exposure. For live imaging, cells were isolated on specific $35 \mathrm{~mm}$ Petri dish with high optical quality bottom for microscopy (IBIDI, Munich, Germany).

\section{Light conditions}

Cells were exposed to $10 \mathrm{~nm}$-wide light bands produced by a custom-made LED-based fibered illumination device for $15 \mathrm{~h}$ as previously described by ${ }^{5}$. Each light band is designated by its central wavelength. Central wavelengths of the narrow light bands were equally distributed from 390 to $520 \mathrm{~nm}$ in $10 \mathrm{~nm}$ increments (14 narrow bands available). A 15th band with a central wavelength set at $630 \mathrm{~nm}$ was added. To model physiological light 
conditions reaching the retina, irradiances for each band of light were calibrated according to a normalized daylight spectrum obtained by applying the natural ocular media filtering of a 40-year-old eye (CIE 203:2012) onto the referenced solar spectrum (ASTM, G173-03, International standard ISO 9845-1, 1992 $2^{5,35}$ ). Accordingly, the $10-\mathrm{nm}$ irradiances varied from $0.01 \mathrm{~mW} / \mathrm{cm}^{2}$ at $390 \mathrm{~nm}$ to $0.56 \mathrm{~mW} / \mathrm{cm}^{2}$ at $630 \mathrm{~nm}$, with $0.39 \mathrm{~mW} / \mathrm{cm}^{2}$ at $440 \mathrm{~nm}$ (Supplementary Fig. S6). Irradiances and spectra were measured using the calibrated spectroradiometer JAZ (Ocean Optics, Dunedin, USA). After a 4-h rest period following seeding in a 96-well plate, cone photoreceptors were either exposed to the physiological solar spectrum or to $0.2 \mathrm{~mW} / \mathrm{cm}^{2}$ for each band of light. After light exposure, cells were maintained in darkness for $24 \mathrm{~h}$ before viability measurement or fixation for immunocytochemistry. Irradiance measurements in real life at the corneal level were assessed using the spectroradiometer JAZ oriented downward with a $-15^{\circ}$ toward a low-reflecting ground (to mimic the head inclination of a person walking) on the fifth floor of a building (GPS coordinates: 48.84983 and 2.372486) with an almost clear view, East orientation, in a sunny morning (11:00 a.m.) in Paris during the summer (August 29th, 2017). Spectral irradiances $\left(\mathrm{mW} / \mathrm{cm}^{2}\right)$ were measured with a $1 \mathrm{~nm}$ step and then integrated over $10 \mathrm{~nm}$ bandwidths to compare to the in vitro irradiances.

\section{Viability measurement}

To assess viability, calcein (Life Technologies) was added to the cell culture medium $24 \mathrm{~h}$ after the end of light exposure and incubated during $1 \mathrm{~h}$. The number of positive viable cells was then counted with an automated microscope equipped with a $\times 10$ objective (Arrayscan, Thermo Scientific, Rockford, IL, USA). Figure if $n=3$ for $390,460,470,510 \mathrm{~nm}, n=4$ for $410,420,450,490$, $500 \mathrm{~nm}, n=5$ for $400,430,440,480,630$. Figure $1 \mathrm{~g} n=5$ for $390,460,470,510,520 \mathrm{~nm}, n=7$ for all other wavelengths. Experiments were excluded when surviving cells in the dark control condition were $25 \%$ below the number of viable seeded cells, indicating a poor quality of the provided retina. Mean of the surviving cells observed in dark control was $50 \%$ of seeded cells.

\section{Immunocytochemistry}

Cone photoreceptors were either fixed in the 96-well plates or Petri dish with $4 \%$ paraformaldehyde after cell isolation during $15 \mathrm{~min}$ at room temperature (PFA, Sigma-Aldrich, St Louis, MO, USA) or $24 \mathrm{~h}$ after the end of light exposure during $1 \mathrm{~h}$ at room temperature. Cells were then washed three times with phosphate buffer saline (PBS) before being permeabilized with PBS $0.1 \%$ Triton X-100 (Sigma) for 3 min at room temperature and washed again three times in PBS. To prevent nonspecific binding cells were incubated during $2 \mathrm{~h}$ at room temperature in a blocking buffer solution containing 1\% BSA (Bovine Serum Albumin, Sigma-Aldrich), 0.05\% Tween 20 (Sigma-Aldrich) in PBS. Cells were immuno-stained overnight at $+4{ }^{\circ} \mathrm{C}$ with a rabbit polyclonal antibody raised against S-opsin (Merck-Millipore, Billerica, MA, USA), a rabbit polyclonal antibody raised against $\mathrm{M}$-opsin (Merck-Millipore), with a rabbit polyclonal antibody directed against the human cone arrestin (LUMIf-hCAR/ human cone arrestin (ARR4), Cheryl Mae Craft, University of Southern California Roski Eye Institute, Los Angeles, $\mathrm{CA}^{36,37}$ ) or with a mouse antibody raised against ATP synthase subunit $b$ (Life Technologies). After primary immunostaining, cells were washed several times with PBS and incubated for $2 \mathrm{~h}$ at room temperature with either anti-rabbit Alexa 594 or anti-mouse Alexa 594 secondary antibodies (Life Technologies). All antibodies were diluted in the blocking buffer solution. Nuclei were counterstained with 4',6-Diamidine-2'-phenylindole dihydrochloride (DAPI, Sigma-Aldrich).

\section{Immunohistochemistry}

For opsin labeling, porcine eyes without anterior segment were fixed with $4 \%$ paraformaldehyde overnight at $+4{ }^{\circ} \mathrm{C}$. Eyes were cryoprotected in successive solutions of PBS containing 10, 20, and $30 \%$ sucrose at $+4{ }^{\circ} \mathrm{C}$ before being embedded in NEG50 (Microm, Francheville, France). Retinal cryosections $(12 \mu \mathrm{m})$ were cut using a cryostat (Microm). For retinal flatmount immuno-labeling, freshly isolated retina were fixed with $4 \%$ paraformaldehyde during $1 \mathrm{~h}$ at room temperature. Retinal piece or sections were incubated $2 \mathrm{~h}$ at room temperature in blocking buffer solution containing PBS, $1 \%$ Triton X100, 5\% BSA, $0.5 \%$ Tween 20 . Retinal tissues or cryosections were immune-stained overnight at $+4{ }^{\circ} \mathrm{C}$ with a rabbit polyclonal antibody raised against $\mathrm{S}$-opsin (AB5407, Merck-Millipore, Billerica, MA, USA), a rabbit polyclonal antibody raised against M-opsin (AB5405, Merck-Millipore), or with a mouse antibody raised against ATP synthase subunit b (A-21351, Life technologies). All antibodies were diluted in the blocking buffer solution. After primary immunostaining, retinal tissues and cryosections were washed several times with PBS and incubated for $2 \mathrm{~h}$ at room temperature with either anti-rabbit Alexa 594 or anti-mouse Alexa 594 secondary antibodies (Life Technologies). Nuclei were counterstained with 4',6Diamidine-2'-phenylindole dihydrochloride (DAPI, Sigma-Aldrich). Retinal tissues and cryosections were then mounted in Permafluor medium (Thermo Fisher Scientific).

\section{Opsin quantification}

After immunocytochemistry, M-opsin and S-opsin positive cells were quantified among purified cone photoreceptors in 
96 well-plates using an automated microscope equipped with a $\times 10$ objective (Arrayscan, Thermo Scientific).

\section{Confocal imaging}

Imaging was performed either on freshly isolated cells or tissues without any fixation step or on immunolabelled samples using an Olympus FV1200 (or FV1000) laserscanning confocal microscope. DAPI counterstaining, autofluorescence, and AlexaFluor-594 were excited using $405 \mathrm{~nm}$ laser diode, $488 \mathrm{~nm}$ argon ion laser, and $559 \mathrm{~nm}$ laser diode lines, respectively. Selections of excitation wavelengths and emission wavelengths were controlled by appropriate filters: dichroic miror (405/488/559/635), emission beam splitters SDM490 (or spectral detection), SDM560 (or spectral detection), SDM640, and barrier filters BA430-470, BA505-540, BA575-675, and BA655-755, respectively. The objectives used were water dipping objective LUMPLFLN 40X NA 0.8-WD 3.3, oil immersion PLAPON 60X SC NA1.4-WD 0.12, UPLSAPO 100X NA 1.4 WD 0.13. Control of the microscope and image acquisition were conducted using Olympus Fluoview software version 4.2. Image acquisition was conducted at a resolution of $1024 \times 1024$ pixels, with a scan rate of $10 \mu \mathrm{s} \mathrm{pixel}^{-1}$. Images were acquired sequentially, line by line, in order to reduce excitation and emission crosstalk, and step size was defined according to the Nyquist-Shannon sampling theorem. Exposure settings that minimized saturated pixels in the final images were used. Twelve bit images were then processed with ImageJ or FIJI, Z-sections were projected on a single plane using maximum intensity under Z-project function and finally converted to 24 bits RGB color images. Figures were then assembled by using Adobe Photoshop $\mathrm{CC}$ and Adobe Illustrator software (Adobe, San Jose, CA, USA).

\section{Fluorescence excitation and emission spectra}

To define the spectral signature of chromophore in cone photoreceptors, freshly isolated retinas were transversally sectioned using a vibrating microtome as described above, a section was place between slide and coverslip in Permafluor mounting medium to expose cone inner segments to wavelengths ranging from 300 to $490 \mathrm{~nm}$ in $15 \mathrm{~nm}$ increments. The corresponding emission spectra were recorded using focused excitation, a high- $\lambda$-pass filter to remove the excitation, and confocal detection with an Andor Shamrock SR303i spectrometer and Andor Ixon 3 EM-CCD (Andor Technology, Belfast, Northern Ireland). The resulting excitation-emission matrix was normalized by the excitation intensity to compensate its spectral variations, although this increases noises below $400 \mathrm{~nm}$, where the available excitation intensity is weaker.

\section{Statistics}

Experiments were repeated at least three times. Results for cell viability and cell type quantifications after light exposure were therefore the averaged values of at least three independent experiments (represented biological replicates). For cell viability measurement, each experiment was the mean of at least three technical replicates. The data were normalized to dark control and represented as mean \pm SEM. Statistical analyzes were performed using GraphPad Prism 7.03 Software (GraphPad Prism, La Jolla, CA, USA). One-way ANOVA followed by Dunnett's post hoc tests were used to compare variances of all groups. Differences between samples and dark control were considered to be significant when $p<0.05$ $\left.{ }^{(*)}\right), p<0.01{ }^{(* *)}, p<0.001{ }^{(* * *)}$ or $p<0.00011^{(* * * *)}$.

\section{Acknowledgements \\ We thank Arthur Planul for artwork, Kate Grieve for carefully reading the manuscript, Anaïs Potey and Elisabeth Dubus for technical assistance. We thank the cell culture, imaging and HTS platforms at the Institut de la Vision. We thank the School of Surgery (Ecole de Chirurgie, Assistance Publique Hôpitaux de Paris) for postmortem human ocular globes. We thank Cheryl Mae Craft (University of Southern California ROSKI Eye Institute, Los Angeles, CA) for providing the antibody (LUMIf-hCAR) for cone arrestin. This work was supported by French state funds managed by the Agence Nationale de la Recherche within the Investissements d'Avenir program, RHU LIGHT4DEAF [ANR-15-RHU-0001], LABEX LIFESENSES [ANR-10-LABX-65], IHU FOReSIGHT [ANR-18-IAHU-0001], [ANR-11-IDEX-0004-02]. It received a grant from the Agence National pour la Recherche for the CHRONOMOFOS project [ANR-12-} TECS-0013] and a grant from Essilor International.

\section{Author details \\ 'Sorbonne Université, INSERM, CNRS, Institut de la Vision, 17 rue Moreau, 75012 Paris, France. ${ }^{2}$ Université de Paris, Campus Saint Germain, 45 rue des Saints Pères, 75006 Paris, France. ${ }^{3}$ Essilor International R\&D, 147 Rue de Paris, 94220 Charenton-Le-Pont, France. ${ }^{4}$ The University of Pittsburgh School of Medicine, 3550 Terrace Street, Pittsburgh, PA 15213, USA. ${ }^{5}$ CHNO des Quinze-Vingts, DHU Sight Restore, INSERM-DGOS CIC 1423, 28 Rue de Charenton, 75012 Paris, France}

\section{Conflict of interest}

Patent by M.M., V.F., C.B., C.E., J-A.S., and S.P. In addition, C.B. and C.E. are Essilor employees. S.P. received honoraria for participating to a meeting organized by Essilor. S.F., P.B., and G.T. declare no competing interests. The authors declare that they have no conflict of interest.

\section{Publisher's note}

Springer Nature remains neutral with regard to jurisdictional claims in published maps and institutional affiliations.

Supplementary Information accompanies this paper at (https://doi.org/ 10.1038/s41419-020-02918-8).

Received: 12 March 2020 Revised: 1 August 2020 Accepted: 3 August 2020 Published online: 29 August 2020

\section{References}

1. Behar-Cohen, F. et al. Light-emitting diodes (LED) for domestic lighting: any risks for the eye? Prog. Retin. Eye Res. 30, 239-257 (2011).

2. Scientific Committee on Health, E. a. E. R. S. Opinion on potential risks to human health of Light Emitting Diodes (LEDs). https://ec.europa.eu/health/ sites/health/files/scientific_committees/scheer/docs/scheer_o_011.pdf (2018). 
3. Rambhatla, P. V., Brescoll, J., Hwang, F., Juzych, M. \& Lim, H. W. Photosensitive disorders of the skin with ocular involvement. Clin. Dermatol. 33, 238-246 (2015).

4. Sui, G. Y. et al. Is sunlight exposure a risk factor for age-related macular degeneration? A systematic review and meta-analysis. Br. J. Ophthalmol. 97, 389-394 (2013).

5. Arnault, E. et al. Phototoxic action spectrum on a retinal pigment epithelium model of age-related macular degeneration exposed to sunlight normalized conditions. PLOS ONE 8, e71398 (2013).

6. Sparrow, J. R., Nakanishi, K. \& Parish, C. A. The lipofuscin fluorophore A2E mediates blue light-induced damage to retinal pigmented epithelial cells. Investig. Ophthalmol. Vis. Sci. 41, 1981-1989 (2000).

7. Noell, W. K., Walker, V. S., Kang, B. S. \& Berman, S. Retinal damage by light in rats. Investig. Ophthalmol. 5, 450-473 (1966).

8. Reme, C. E. The dark side of light: rhodopsin and the silent death of vision the proctor lecture. Investig. Ophthalmol. Vis. Sci. 46, 2671-2682 (2005).

9. Fain, G. L. \& Lisman, J. E. Light, $\mathrm{Ca}^{2+}$, and photoreceptor death: new evidence for the equivalent-light hypothesis from arrestin knockout mice. Investig. Ophthalmol. Vis. Sci. 40, 2770-2772 (1999).

10. Organisciak, D. T. \& Vaughan, D. K. Retinal light damage: mechanisms and protection. Prog. Retin Eye Res. 29, 113-134 (2010).

11. Grimm, C. et al. Protection of Rpe65-deficient mice identifies rhodopsin as a mediator of light-induced retinal degeneration. Nat. Genet. 25, 63-66 (2000).

12. Sperling, H. G., Wright, A. A. \& Mills, S. L. Color vision following intense green light exposure: data and a model. Vis. Res. 31, 1797-1812 (1991).

13. Kanan, Y., Moiseyev, G., Agarwal, N., Ma, J. X. \& Al-Ubaidi, M. R. Light induces programmed cell death by activating multiple independent proteases in a cone photoreceptor cell line. Investig. Ophthalmol. Vis. Sci. 48, 40-51 (2007).

14. Krishnamoorthy, R. R. et al. Photo-oxidative stress down-modulates the activity of nuclear factor-kappaB via involvement of caspase-1, leading to apoptosis of photoreceptor cells. J. Biol. Chem. 274, 3734-3743 (1999).

15. Natoli, R. et al. The role of pyruvate in protecting $661 \mathrm{~W}$ photoreceptor-like cells against light-induced cell death. Curr. Eye Res. 41, 1473-1481 (2016).

16. Balse, E. et al. Purification of mammalian cone photoreceptors by lectin panning and the enhancement of their survival in glia-conditioned medium. Investig. Ophthalmol. Vis. Sci. 46, 367-374 (2005).

17. Sharma, R., Williams, D. R., Palczewska, G., Palczewski, K. \& Hunter, J. J. Twophoton autofluorescence imaging reveals cellular structures throughout the retina of the living primate eye. Investig. Ophthalmol. Vis. Sci. 57, 632-646 (2016).

18. Boulton, M., Rozanowska, M. \& Rozanowski, B. Retinal photodamage. J. Photochem. Photobiol. B 64, 144-161 (2001).

19. Monici, M. Cell and tissue autofluorescence research and diagnostic applications. Biotechnol. Annu. Rev. 11, 227-256 (2005).

20. Croce, A. C.\& Bottiroli, G. Autofluorescence spectroscopy and imaging: a tool for biomedical research and diagnosis. Eur. J. Histochem. 58, 2461 (2014).
21. Kam, J. H. et al. Mitochondrial absorption of short wavelength light drives primate blue retinal cones into glycolysis which may increase their pace of aging. Vis. Neurosci. 36, E007 (2019).

22. Papayan, G., Petrishchev, N. \& Galagudza, M. Autofluorescence spectroscopy for $\mathrm{NADH}$ and flavoproteins redox state monitoring in the isolated rat heart subjected to ischemia-reperfusion. Photodiagnosis Photodyn. Ther. 11, 400-408 (2014).

23. Benson, R. C., Meyer, R. A., Zaruba, M. E. \& McKhann, G. M. Cellular autofluorescenc-is it due to flavins? J. Histochem. Cytochem. 27, 44-48 (1979).

24. Narayan, D. S., Wood, J. P., Chidlow, G. \& Casson, R. J. A review of the mechanisms of cone degeneration in retinitis pigmentosa. Acta Ophthalmol. 94, 748-754 (2016).

25. dos Santos, A. F., de Almeida, D. R. Q., Terra, L. F., Baptista, M. S. \& Labriola, L. Photodynamic therapy in cancer treatment-an update review. J. Cancer Metastasis Treat. 5, 25, https://doi.org/10.20517/2394-4722.2018.83 (2019).

26. Kou, J., Dou, D. \& Yang, L. Porphyrin photosensitizers in photodynamic therapy and its applications. Oncotarget 8, 81591-81603 (2017).

27. Sternberg, E. D, D. \& C, B. Porphyrin-based photosensitizers for use in photodynamic therapy. Tetrahedron 54, 4151-4202 (1998).

28. Vandersee, S., Beyer, M., Lademann, J. \& Darvin, M. E. Blue-violet light irradiation dose dependently decreases carotenoids in human skin, which indicates the generation of free radicals. Oxid. Med. Cell Longev. 2015, 579675 (2015).

29. Lee, J. B. et al. Blue light-induced oxidative stress in human corneal epithelial cells: protective effects of ethanol extracts of various medicinal plant mixtures. Investig. Ophthalmol. Vis. Sci. 55, 4119-4127 (2014).

30. Kaido, M. et al. Reducing short-wavelength blue light in dry eye patients with unstable tear film improves performance on tests of visual acuity. PLOS ONE 11, e0152936 (2016).

31. Chen, Y., Liu, Y. \& Dorn, G. W. II Mitochondrial fusion is essential for organelle function and cardiac homeostasis. Circ. Res. 109, 1327-1331 (2011).

32. Young, R. W. Solar radiation and age-related macular degeneration. Sur Ophthalmol. 32, 252-269 (1988).

33. Sliney, D. H. Exposure geometry and spectral environment determine photobiological effects on the human eye. Photochem. Photobiol. 81, 483-489 (2005).

34. Pastuszka, M. et al. Ocular findings in Polish Armed Forces in Iraq and Afghanistan, a review of medical examinations by The Military Medical Commission in Lodz. Klin. Ocz. 115, 296-299 (2013).

35. Marie, M. et al. Light action spectrum on oxidative stress and mitochondrial damage in A2E-loaded retinal pigment epithelium cells. Cell Death Dis. 9, 287 (2018).

36. Zhang, Y. et al. in Retinal Degeneration Diseases and Experimental Therapy (eds Hollyfield, J. G., Anderson, R. E., \& LaVail, M. M.) 309-318 (Kluwer Academic Plenum Publishers, 2001).

37. Craft, C. M., Huang, J., Possin, D. E. \& Hendrickson, A. Primate short-wavelength cones share molecular markers with rods. Adv. Exp. Med. Biol. 801, 49-56 (2014). 